\title{
Future scenarios and opportunities for interventional radiology in the post COVID-19 era
}

\author{
Jose Maria Abadal (D) \\ Jimena Gonzalez-Nieto (D) \\ Fernando Lopez-Zarraga (D) \\ Miguel Angel de Gregorio (D) \\ Panagiotis M. Kitrou (1) \\ Santiago Mendez (D)
}

Department of Vascular and Interventiona Radiology (J.M.A. $₫$ jmabadal@yahoo.es), Severo Ochoa University Hospital, Madrid, Spain; Department of Vascular and Interventional Radiology (J.G.N.), San Carlos Clinical Hospital, Madrid, Spain; Department of Vascular and Interventional Radiology (F.L.Z.), Álava University Hospital, Álava, Spain; Department of Vascular and Interventional Radiology (M.A.D.G.), Zaragoza Clinical University Hospital, Zaragoza, Spain; Department of Vascular and Interventional Radiology (P.M.K.), Patras University Hospital, Patras, Greece; Department of Vascular and Interventional Radiology (S.M.), Puerta de Hierro University Hospital, Madrid, Spain.

Received 18 July 2020; revision requested 23 July 2020; last revision received 11 August 2020; accepted 14 August 2020.

Published online XXXXXXXXX.

DOI 10.5152/dir.2020.20494

\begin{abstract}
Pandemic outbreak has led health systems worldwide into a rapid reorganization in response to coronavirus infections, forcing interventional radiology units to adapt. Interventional procedures have evolved in number, type and setting and have arguably been optimized as a direct consequence of this pandemic; a result that will undoubtedly lead to radical change within the specialty. This paper explores the future of interventional radiology from various perspectives, and forecasts the new opportunities that will be presented, from the adaptation of the interventional radiology staff and angiography suite, to the immunological environment, and through to digital medical education. We analyze the economic impact and the future relationship we can expect with the rest of the medical industry.
\end{abstract}

R apid outbreak of the coronavirus disease 2019 (COVID-19) has led to an unprecedented knockdown of health systems worldwide. During the first weeks of the pandemic, a rapidly growing number of patients required immediate hospitalization, and many of them were admitted to intensive care units (ICU). Human, economic, and medical resources have been redistributed to fight against the pandemic spread. Widely varied rates of virus evolution in terms of time and severity have been observed between the nations, and whilst this allows us to theorize on the course of the disease, many uncertainties remain as how the disease will evolve in the short- to midterm (1).

Narrowing to the field of interventional radiology (IR), we have been forced to adapt our practices to this situation in a very short period of time. An abrupt stop was made to daily practices, with priority being given to only the most urgent oncologic and trauma procedures, and other basic services necessary to fight against the disease on the front line.

The purpose of this article is to explore how IR may evolve over the next 1-3 years. The authors do not pretend to predict or fix ideas about what will happen, rather, they share hypothesis on what may occur, with the aim to spark meaningful reflection and debate. This article has been designed to inspire bold thinking about this inevitable era of change and opportunity, always with the conviction that our "resilient" specialty will prevail as it has done for generations.

\section{Stages of the pandemic and IR procedures}

The course of the COVID-19 infection has been represented as an epidemic curve that shows progression of illnesses in an outbreak over time (Fig. 1).

In the early stages of the "emergency phase" (the period of time until the peak of active cases is reached), when more than $75 \%$ of the hospital admissions were identified as COVID-19 patients, IR units ceased daily activities. From this point, emergent procedures (e.g., bleeding embolization, acute dialysis interventions, TIPS, ruptured EVAR, nephrostomy), and selected nondeferrable oncologic treatments (e.g., ports), were performed. Non-priority procedures (e.g., ovarian vein embolization) were rescheduled or postponed until further notice (2-5).

Only once a health system enters the "mitigation phase", demonstrates a flattening of the curve, and experiences a reduction of new cases ( $25 \%-75 \%)$, an attempt to recover common 
IR activities may start. Initially, IR units will need to be redesigned to create COVID/nonCOVID-19 circuits, and to prepare for future pandemic waves. Until this is accomplished, secondary procedural priorities (e.g., TACE, ablations) will not commence. In this phase, it will be essential to establish circuits and create protocols, though problems may arise due to uncertainty surrounding the immunological status of particular patients who access the angiography suite.

The third phase will arise during the "recovery stage" with the progressive restoration of normal hospital activity $(<25 \%$ COVID-19). As soon as a safe virus environment is assured, common IR procedures will be performed. A surge of patient population can be reasonably expected considering the number of rescheduled or postponed appointments for non-critical procedures when the disease was prevalent.

COVID-19 has also modified the way in which IR procedures were performed. During the emergency phase, there was a tendency to perform bedside procedures for a variety of reasons, such as the clinical status of the patient, the insufficient staff or personnel to transfer patients, and the incomplete adaptation of the IR unit $(3,4)$. IR procedures were carried out in ICU, internal medicine wards, and even makeshift hospitals, under ultrasonography, in adverse conditions. Most frequent interventions were the application of vascular catheters, chest/abdomen drain tubes, and cholecystostomy.

Another possible adaptation to the COVID-19 environment would be optimizing procedures, to delay or even avoid the pa-

\section{Main points}

- Interventional radiology (IR) procedures have evolved in number, type and setting and have arguably been optimized as a direct consequence of this pandemic; a result that will undoubtedly lead to radical change within the specialty.

- A reorganization of the work system must be devised within the IR units that caters for inpatients and outpatients.

- New designs for angiography suites will be necessary for the future.

- The coronavirus pandemic appears to be an inflection point that has accelerated changes in medical education. The spread of the virus is educating us on global connectivity.

- IR will have to catch up with the other medical disciplines, where health management has been implemented and has justified their activities.

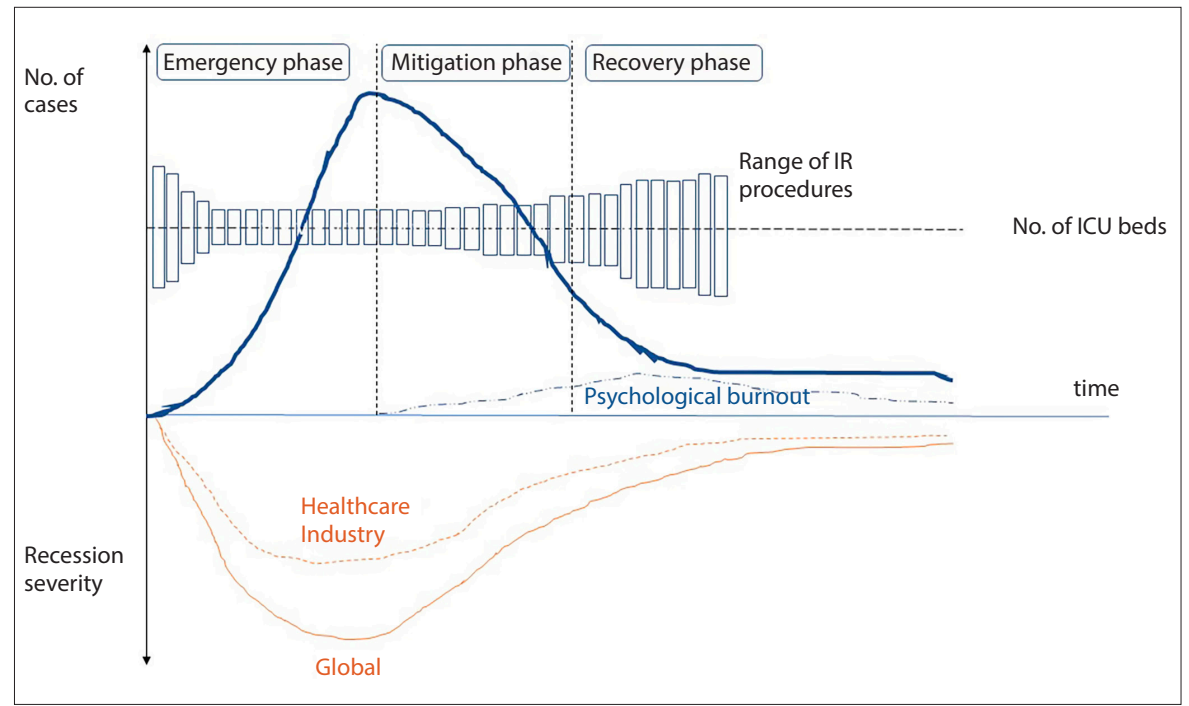

Figure 1. COVID-19 epidemic curve: Curve can be divided in emergency (disease outbreak up to peak), mitigation (flattening curve) and recovery phases. Normally, a return to basal situation can be achieved, but resurgence of a new pandemic wave can occur depending on the management of the mitigation phase. Each phase demands different intensity of medical specialties, hospital beds, and equipment. Health resources are redistributed. IR plays distinct roles depending on the phase.

tient entering the hospital. For example, by distancing catheter exchanges in nephrostomy/gastrostomy tubes, or by scheduling patients requiring ablation and/or biopsies in the first part of the day so they could be managed as outpatients. This promotion of confinement would protect patients by reducing or avoiding intra-hospital infection altogether. IR consultation optimization (1day pre-operative examination) and the use of digital platforms for patient follow-up may be key measures (Table 1).

\section{Adaptation of IR physicians}

Virus protection

With a higher proportion of healthcare professionals (HCP) affected by COVID-19, specific training in virus transmission and contagion prevention in the IR units will be mandatory.

According to the information published by the Centre for Disease Control, the proper use of complete personal protective equipment (PPE), including respirator, will diminish highrisk exposure, enabling a safe working environment for staff (11). Many patients treated in the IR angiography suite might have an active COVID-19 disease. Moreover, some IR procedures are considered as high-risk due to the possibility of aerosolization, such as intubation/extubation, airway/oral suctioning, nasogastric tube insertion, gastrostomy, tracheal/esophageal/gastroduodenal stenting and lung biopsies/bronchial artery embolization $(3,12)$.
Institutions need to provide adequate PPE and the education and training necessary to ensure its correct use to avoid contamination on clothes, skin, and the environment during the doffing procedure. Future education leaders, "buddy-check systems" and COVID-19 checklists to accomplish these new protocols will be needed (12).

\section{Immunological evaluation}

Hospitals must provide security for both patients and professionals by avoiding cross-infection. This will be reliant on the hospital's epidemiological characteristics, as well as the availability of diagnostic tests (PCR and serological tests). Patient immunological status may be controlled at different levels, by performing tests on all patients, on those patients with risk factors (e.g., cardiovascular disease, immunosuppression, over 70 years of age), or as a minimum, on those who will undergo procedures requiring hospital admission. Regardless of the test protocol implemented, the hospital must be informed in advance of COVID-19 positive patients that access the IR unit, the objective being to avoid complications caused by COVID-19 infection and contamination of the otherwise clean hospital circuit $(13,14)$.

It is necessary to carry out immunological and PCR tests for HCP in order to identify COVID-19 cases (Fig. 2). For asymptomatic professionals, this would determine those who can transmit the virus (PCR+) 
and should remain isolated, and those who could work normally (PCR-). Symptomatic HCP should undergo a PCR study directly, with routine and repetitive surveillance of all negative HCP, depending on the stage of the pandemic and the recommendations of the local health authority at that time (13-16).

\section{IR work redesign}

A reorganization of the work system must be devised within IR units that caters for inpatients and outpatients. Prior to COVID-19

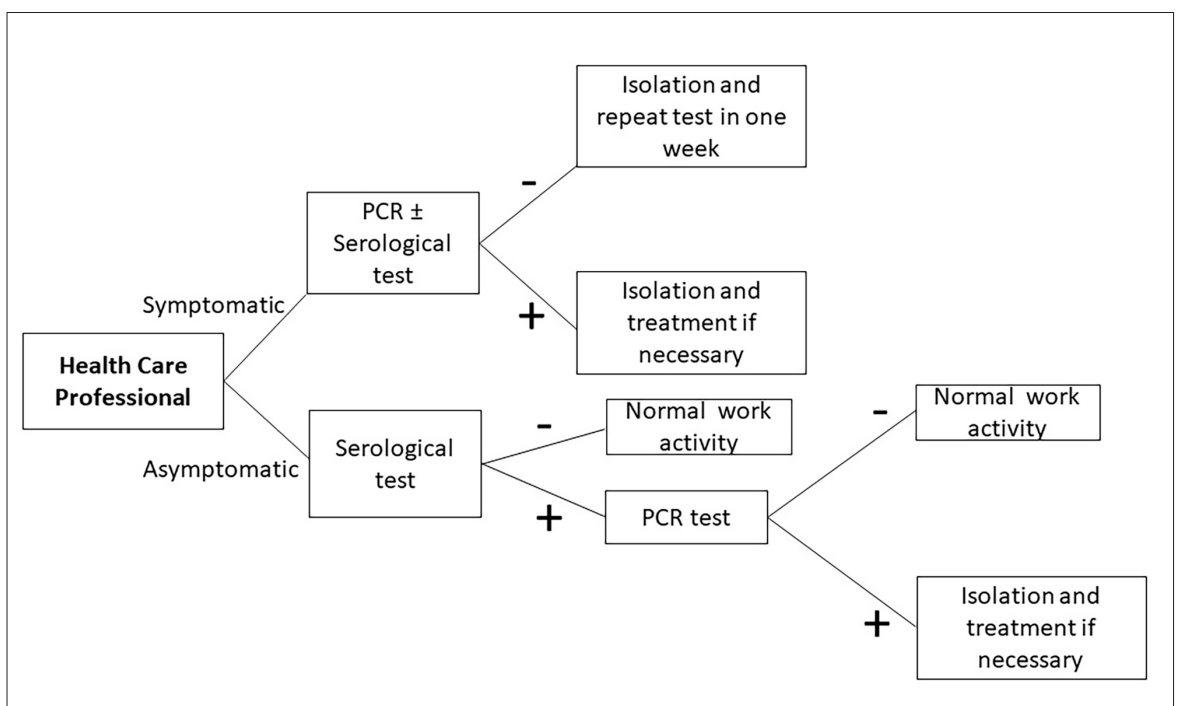

Figure 2. Immunological and molecular testing protocol proposed for IR personnel (could be modified according to the available evidence and the indications of local public health authorities). rationalize the work of IR team during critical pandemic scenarios. In this situation, protocols would contemplate continuity of patient care by distributing staff into non-interchangeable fixed groups.

\section{Psychological impact in IR}

The healthcare community is facing unprecedented physical and psychological stress. The term "resilience" will be definitively incorporated as one of our core values. In addition to the inherent stress associated with medical decision-making, we now contemplate new infectious risk management. COVID-19 anxiety in IR staff has been present from the outset due to the lack of adequate protective material and the clear instructions of its use. This anxiety has persisted into the second stage of the pandemic, with the added responsibility to re-fashion IR wards to cater for COVID-19 and non-COVID-19 patients and provide safe and secure environments and working procedures at all times.

In the late pandemic period, we will be faced with long waiting lists for postponed procedures, resulting in increased workload on professionals, working within a specialty where only the highest quality of service can be accepted. This requirement will materialize in a time when we can reasonably anticipate downward budgetary pressure, salary caps, headcount reductions, and limited

\begin{tabular}{|c|c|c|}
\hline Optimization strategy & Objectives & Actions \\
\hline \multirow[t]{3}{*}{ 1. Vascular access } & - Reduce hospital stay & $\begin{array}{l}\text { - Radial access for diagnostic and therapeutic } \\
\text { procedures }\end{array}$ \\
\hline & - Reduce procedure times & - Vascular closure devices $(7,8)$ \\
\hline & - Social distancing & \\
\hline 2. Drainage catheters & - Reduce waiting list & - High durability materials \\
\hline 3. Biliary system procedures & $\begin{array}{l}\text { - Reduce number of interventions per patient } \\
\text { - } \quad \text { Reduce hospital stay }\end{array}$ & $\begin{array}{l}\text { - Biliary stent placement in the same initial } \\
\text { drainage procedure }\end{array}$ \\
\hline \multirow{4}{*}{ 4. Early discharges } & & $D$ First procedure of the day \\
\hline & & $\Delta$ Telephone follow-up the next day \\
\hline & & $\begin{array}{l}\text { Use of opioid-free analgesic protocols if } \\
\text { possible }\end{array}$ \\
\hline & & D Use local anesthetic in all patients \\
\hline
\end{tabular}




\section{Table 2. Structural adaptation of IR units to COVID-19}

In units with two or more angiography suites, it is recommended to establish one for COVID-19 patients and one for non-COVID-19. Separate circuits of patient management should be mandatory.

In IR units with one angiographic room, it is recommended to segregate different groups of patients. If possible, procedures for non-infected patients should be performed in the early hours of the day and those for the infected in the second part of the workday.

Ideally, staff should not work simultaneously with both types of patients during the workday and it is advisable to change staff uniforms after performing procedures on COVID-19 patients. Interchangeable personnel shifts may be employed. For example, interventional radiology staff may work for a week and are isolated for the following week at home.

The equipment of COVID-19 and non-COVID-19 rooms must be separated and non-interchangeable.

In COVID-19 rooms, this equipment will be essential for operation and must be properly protected and disinfected.

All fixed wardrobes inside the angiography suite should be replaced by mobile wardrobes and trolleys.

Material storage should be redesigned to optimize access to frequently used devices and minimize transfers.

There should be no coexistence of COVID-19 and non-COVID-19 patients in hallways, waiting or recovery rooms.

It is necessary to take into account the increase in the time of transfers, procedures and cleaning protocols after interventions in COVID-19 patients, regardless of the complexity of the procedure.

A dedicated, specifically trained $24 / 7$ cleaning team, with a sanitization sequence might prove to be a valuable resource.

availability of resources, the obvious results of global recession, possibly even depression, the normal outcome of any pandemic.

Two types of uncertainty related to the disease will be presented. First, with respect to medical aspects of the disease (variety of symptoms, development of immunity, future medication/vaccine and possible new pandemic waves), and second, the personal aspect, related to our social-family setting (fear of becoming an infectious vector for our beloved).

Depression, anxiety, and post-traumatic syndrome will be observed with a variety of symptoms (asthenia, anorexia, sleep disorder, nervousness) (17-19). As time passes and the pandemic stimulus ends, we will progressively learn to manage these situations. Disease updates and medical training in virus protective measures will relieve stress levels. Fluid communication channels that encourage the sharing of experiences will be established. Psychological support may be required. Leadership should especially be aware of burn-out and psychological pandemic impact amongst the teams (20).

Angiography suite adaptation to COVID-19

Significant changes are taking place in healthcare facilities as a consequence of the COVID-19 pandemic, and IR services have been driven to implement structural changes of their units.

Improvised and non-protocol actions have been taken in the angiography suite during the emergency phase. As the scenario improved, and normal activity resumed, the co-existence of COVID-19 and non-COVID-19 patients has led to the creation of two separated circuits, supervised by the preventive medicine service $(14,16)$. The authors have listed below recommendations to adapt IR unit facilities to the conditions of the the pandemic (Table 2).

New designs for angiography suites will be necessary in the future. They may include disinfection corridors, negative pressure rooms (airborne infection isolation), high air exchange cycle rate rooms, antiviral surface coating with zinc dioxide or silver nanoparticles and ultraviolet disinfection devices (21-23).

\section{Continuing medical education (CME) in IR}

The coronavirus pandemic appears to be an inflection point that has accelerated changes in medical education. The spread of the virus is educating us on global con- nectivity. Tools such as Zoom (Zoom Video Communications Inc.), and Slack (Slack Technologies Inc.), have enabled simultaneous communication amongst hundreds of specialists (including IR), with medical leaders in differing countries sharing their experiences and learning from the pandemic in real time (24). Live streamed webinars have become the mainstay of medical educational platforms during the acute phase of COVID-19 infection, and will probably become standard for the future. The on-demand option will increase the audience to IR that would prefer to consume the content on their terms and avoid technical risks. The drawback of webinars, however, is the limited participation, reduced to a non-interactive submitted question. To solve this lack of collaboration, the implementation of small group meetings within online forums is suggested.

Medical congresses have also been affected due to the COVID-19 restrictions. International conferences and courses such as GEST, CIRSE, SIR and ECIO, as well as local meetings have been cancelled, postponed or have been redesigned as "virtual". We can expect new European legislation detailing updated regulation with respect to social distancing at medical events. Virtual congresses may be the inevitable reality for the future. A complete change of mind set amongst physicians, and an industry-wide deployment plan will be required (25-27).

Social networks will allow us to share knowledge and collaborate in real time. For example, the social networks Twitter and WhatsApp allow people to learn and share information on a global scale, without the depth, supervision, or need to organize classical medical meetings. IR, however, will need trusted content within social networks in order to be effective for CME, and to avoid "infodemic" channels of misinformation (28).

As IR is a hands-on-learning discipline, IR fellows will need to learn demonstrable skills in the context of limited access to clinical rotations and collaborative experiences. Live cases, recorded cases, tele-mentoring and IR unit rotations within safe COVID-19 environments may solve this setback.

Artificial intelligence, robotics and virtual reality are highly likely to be essential components for adaptive learning.

Despite this future trend of technology utilization, we cannot ignore how important face-to-face contact and in-person learning is for IR in the context of CME. 


\section{Economic impact in IR}

The COVID-19 pandemic has led to a redistribution of healthcare expenditure towards specific hospital units (e.g., ICU, internal medicine), technology (ventilators, portable X-ray units), personal protective equipment, immunological test and medications.

Global gross domestic product (GDP) is expected to decline by between $2.1 \%$ and $3.9 \%$ depending on the impact of the pandemic, with the context of having spent up to $20 \%$ of its GDP on healthcare expenditures (29). In this panorama of scarce public health resources, prioritized to medical and investigative areas related to COVID-19 pandemic, IR units' budgetary forecast will not be very favorable (30). From our side, IR is a novel specialty highly dependent on technology, implying high cost of interventions. From an opportunity cost viewpoint of healthcare intervention investment, IR can be adversely affected (e.g., an endovascular dialysis arteriovenous fistula creation program may be displaced by a COVID-19 telehealth service program). Most likely only the scientifically well-proven interventions and emergency procedures will prevail following the anticipated hospital budgetary cuts.

Unproven technology and interventions, and interventions that do not reach the thresholds of cost-effectiveness, may be suspended or replaced with alternative approaches, perhaps in some cases resulting in a backward step to more classical surgeries. IR will have to catch up with other medical disciplines where health management has been implemented and has justified their activities. In this regard, deep understanding and implementation of healthcare analytics of our practice will be critical. Data collection and analysis, not only from a scientific perspective, but also from economic viewpoint, will be necessary to enable better targeting of financial resources within the IR sector. In evaluating cost-effectiveness, IR has an advantageous position over other specialties, given the minimally invasive nature of interventions and comparably early hospital discharges.

In this context, IR will have to evolve, from optimization/standardization of interventions, to well-established healthcare procedures, to facilitate improved relationships with hospital managers within an economically pressured environment. Medical supplies will also need adjustment to re- duce the cost of IR products, with varying strategies, in order to achieve homogeneity in product cost between hospitals (e.g., centralized supply). Marketing will also play an important role in order to assure access of the patient to the IR units in an unstoppable tendency of digital media and social networks.

\section{Relations with the medical industry}

When this healthcare crisis passes, the healthcare sector would have been transformed, perhaps unrecognizable from its former self. With a global view, health companies with multiple divisions, or that fulfill the critical needs of the COVID-19 markets, will be in a good financial position, whilst others specialized in IR may experience a slowdown of their business. Revenue has fallen during the outbreak; whilst the mitigation phase is in progress, elective procedures will return to redress business losses, though this does not imply that revenues will recover their previous levels. Payment disruption to providers will increase and IR product margins will be negatively affected. IR companies will need to create challenging strategies in diverse areas such as staffing, medical and financial departments.

COVID-19 has built a barrier between IR staff and traditional sales representatives. Medical centers have restricted access of sales representatives to hospitals in order to minimize the virus spread in communities. Creative marketing initiatives based on digital technology (webinars, videoconferences with customers, podcasts) may replace traditional branding. Highly qualified product specialists may become the only representatives permitted access to hospital and support physicians. This tendency may require future restructuring of companies, resulting in job losses, while remaining job profiles are enhanced.

In many countries, a great part of $\mathrm{CME}$ has relied on the healthcare industry. Social distancing recommendations and future infectious waves may alter the organization of traditional medical congress and events where the industry plays an import role by offering educational grants and sponsorship. Industry CME support will be carried out through digital alternatives like webinars, small group conferences, and e-learning platforms, with software to evaluate medical activity and patient follow-up being in high demand.

\section{Conclusion}

The COVID-19 pandemic outbreak has transformed our healthcare system and medical practices. IR will need to adapt to meet the challenges of a dynamic and uncertain future. We will be required to demonstrate our new core value of resilience, to adapt, to improve, to rise into those challenges, to streamline our IR facilities and practices, to enhance relationships with our peers, our managers, and the medical industry as a whole.

Conflict of interest disclosure

The authors declared no conflicts of interest.

\section{References}

1. Kissler SM, Tedijanto C, Goldstein E, Grad YH, Lipsitch M. Projecting the transmission dynamics of SARS-CoV-2 through the postpandemic period. Science 2020; 368:860-868. [Crossref]

2. Lei S, Jiang F, Su W, et al. Clinical characteristics and outcomes of patients undergoing surgeries during the incubation period of COVID-19 infection. EClinicalMedicine 2020 Apr 5; 100331. [Crossref]

3. De Gregorio MA, Serrano L, López Zárraga F, et al. Guidelines for vascular and interventional radiology units during the COVID-19 outbreak: a consensus statement from the Spanish Society of Vascular and Interventional Radiology (SERVEI) Marzo-2020. Available at: https://servei.org/wp-content/uploads/Guidelines-for-vascular-and-interventional-radiology-units-during-the-COVID-19-outbreak.pdf

4. Ierardi AM, Wood BJ, Gaudino C, et al. How to handle a COVID-19 patient in the angiographic suite. Cardiovasc Intervent Radiol 2020; 43:820-826. [Crossref]

5. Chandy $P E$, Nasir MU, Srinivasan $S$, Klass $D$, Nicolaou S, Babu S. Interventional radiology and COVID-19: evidence-based measures to limit transmission. Diagn Interv Radiol 2020; 26:236-240. [Crossref]

6. Kim HY, Choo SW, Roh HG, et al. Efficacy of femoral vascular closure devices in patients treated with anticoagulant, abciximab or thrombolytics during percutaneous endovascular procedures. Korean J Radiol 2006; 7:35-40. [Crossref]

7. Noori VJ, Eldrup-Jørgensen J. A systematic review of vascular closure devices for femoral artery puncture sites. J Vasc Surg 2018; 68:887899. [Crossref]

8. Sheth RA, Koottappillil B, Kambadakone A, Ganguli S, Thabet A, Mueller PR. A quality improvement initiative to reduce catheter exchange rates for fluoroscopically guided gastrostomy tubes. J Vasc Interv Radiol 2016; 27:251-259. [Crossref]

9. Chen JX, Guzzo TJ, Malkowicz SB, et al. Complication and readmission rates following sameday discharge after percutaneous renal tumor ablation. J Vasc Interv Radiol 2016; 27:80-86. [Crossref] 
10. Nasser F, Cavalcante RN, Galastri FL, et al. Safety and feasibility of same-day discharge of patients with hepatocellular carcinoma treated with transarterial chemoembolization with drug-eluting beads in a liver transplantation program. J Vasc Interv Radiol 2014; 25:10121017. [Crossref]

11. Centers for Disease Control and Prevention. Information for healthcare professionals about coronavirus (COVID-19). Available at: www.cdc. gov/coronavirus/2019-nCoV/hcp/index.html

12. Checklist for preparing your IR service for COVID-19. COVID-19 resource centre. Available at: https://www.cirse.org/wp-content/ uploads/2020/04/CIRSE_APSCVIR_Checklist_ COVID19.pdf

13. Documento técnico. Guía para la utilización de test rápidos de anticuerpos para COVID-19. Versión del 7 de abril de 2020. Ministerio de Sanidad. Gobierno de España. Available at: www.mscbs.gob.es

14. Asociación española de cirujanos. Documentos de posicionamiento y recomendaciones de la AEC en relación con la cirugía y COVID-19Recomendaciones de gestión para la vuelta a normalidad y "desescalada" en los servicios de cirugía general en el contexto de la pandemia COVID-19. Available at: www.aecirujanos.es/ files/noticias/152/documentos/Vuelta_a_la_ normalidad(1).pdf

15. Documento técnico. Guía de actuación frente a COVID-19 en los profesionales sanitarios y socio-sanitarios. Versión del 13 de abril de 2020. Ministerio de Sanidad. Gobierno de España. Available at: www.mscbs.gob.es

16. Informe técnico de la Sociedad Española de Medicina Preventiva, Salud Publica e Higiene. Propuesta de medidas y cuestiones a considerar para la fase de transición de la pandemia por SARS.CoV-2 en España. Available at: https:// www.sempsph.com/images/Informe $\% 20$ SEMPSPH.\%20Propuesta\%20de\%20medidas $\% 20 y \% 20$ aspectos $\% 20$ a $\% 20$ considerar\%20en\%20la\%20fase\%20de\%20transición. pdf
17. Tan BYQ, Chew NWS, Lee GKH, et al. Psychological impact of the COVID-19 pandemic on health care workers in Singapore. Ann Intern Med 2020; 173:317-320. [Crossref]

18. Matsuishi K, Kawazoe A, Imai H, et al. Psychological impact of the pandemic (H1N1) 2009 on general hospital workers in Kobe. Psychiatry Clin Neurosci 2012; 66:353-360. [Crossref]

19. McAlonan GM, Lee AM, Cheung V, et al. Immediate and sustained psychological impact of an emerging infectious disease outbreak on health care workers. Can J Psychiatry 2007; 52:241-247. [Crossref]

20. Brooks SK, Webster RK, Smith LE, et al. The psychological impact of quarantine and how to reduce it: rapid review of the evidence. Lancet 2020; 395:912-920. [Crossref]

21. Tsai YH, Wan GH, Wu YK, Tsao KC. Airborne severe acute respiratory syndrome coronavirus concentrations in a negative-pressure isolation room. Infect Control Hosp Epidemiol 2006; 27:523-525. [Crossref]

22. Ghosh, S. K. Anti-viral surface coating to prevent spread of novel coronavirus (COVID-19) through touch. Nova Surface-Care Centre Pvt. Ltd. 04.15.20. Available at: www. coatingsworld.com/content-microsite/cw covid-19/2020-04-15/anti-viral-surface-coating-to-prevent-spread-of-novel-coronaviruscovid-19-through-touch

23. Dökdök M, Karaman K. UV disinfection as an adjunctive method in the interventional suite. Diagn Interv Radiol 2020; 26:514.

24. Almarzooq Z, Lopes $M$, Kochar A. Virtual learning during the COVID-19 pandemic: A disruptive technology in graduate medical education. J Am Coll Cardiol 2020; 75:2635-2638. [Crossref]

25. Weissgerber T, Bediako Y, De Winde C, et al. Mitigating the impact of conference and trave cancellations on researchers futures. Elife 2020 Mar 27; 9e57032. [Crossref]

26. Achakulvisut T, Ruangrong T, Bilgin I, et al. Improving on legacy conferences by moving online. Elife 2020 Apr 20; 9e57892. [Crossref]
27. Reshef O, Aharonovich I, Armani AM, et al. How to organize an online conference. Nat Rev Mater 2020 Mar 18. [Epub Ahead of Print] [Crossref]

28. Nielsen RK, Fletcher R, Newman N, et al. Navigating the 'infodemic': how people in six countries access and rate news and information about coronavirus. Available at: https:// reutersinstitute.politics.ox.ac.uk/

29. Maliszewska M, Mattoo A, Van Der Mensbrugghe D. (2020). The potential impact of COVID-19 on GDP and trade: a preliminary assessment. World Bank Policy Research Working Paper, (9211). [Crossref]

30. Laxminarayan R, Chow J, Shahid-Salles SA. Intervention cost-effectiveness: overview of main messages. In: Jamison DT, Breman JG, Measham AR, Alleyne G, Claeson M, Evans $D B$, Jha P, Mills A, Musgrove $P$, editors. Disease control priorities in developing countries. 2nd edition. Washington (DC): World Bank; 2006. Chapter 2. 